\title{
Insulin alleviates the inflammatory response and oxidative stress injury in cerebral tissues in septic rats
}

Qiyi Chen ${ }^{\dagger}$, Wenkui Yu', Jiangliang Shi, Juanhong Shen, Tao Gao, Juanjuan Zhang, Fengchan Xi, Jieshou Li and Ning Li

\begin{abstract}
Sepsis-associated encephalopathy (SAE) is a diffuse brain dysfunction that occurs secondary to infection in the body without overt central nervous system (CNS) infection. SAE is frequently encountered in critically ill patients in intensive care units and can be detected in up to 50-70\% of septic patients. Previous studies have demonstrated that inflammatory cytokine release and oxidative stress injury are major pathophysiological mechanisms of SAE in critically ill patients. However, there are no effective strategies for the treatment of SAE. Insulin has important immunomodulatory effects and protective effects against oxidative stress injury in the peripheral organs of septic patients. However, very few studies of the possible effects of insulin in cerebral tissues of septic patients have been reported. Therefore, in this study, we aimed to explore whether insulin therapy can inhibit cytokine production (IL-1, IL-6, and TNF-a) and oxidative stress injury of the brain tissue in septic rats. We observed that the protein concentrations of IL-1, IL-6, and TNF-a, in addition to MDA and $\mathrm{H}_{2} \mathrm{O}_{2}$ were notably increased, inversely SOD, and GSH were sigificantly decreased in cortex, hippocampus, and hypothalamus of septic rats. Furthermore, the levels of S100 and NSE significantly increased. After 6 hours of insulin therapy, we found that the cytokine concentrations notably decreased and oxidative stress injuries in the cortex, hypothalamus, and hippocampus were alleviated in septic rats. In addition, the S100 and NSE levels significantly decreased. We concluded that insulin can inhibit the production of inflammatory cytokines and the oxidative stress response, thereby improving brain tissue damage.
\end{abstract}

Keywords: Sepsis, Sepsis-associated encephalopathy, Inflammation, Oxidative stress, Neurologic injury

\section{Introduction}

Sepsis-associated encephalopathy (SAE) is a diffuse brain dysfunction that occurs secondary to infection in the body in the absence of central nervous system (CNS) infection. SAE is often observed in critically ill patients and can be detected in up to $50-70 \%$ of septic patients $[1,2]$. However, there are no effective treatment strategies for SAE. The severity of SAE can range from mild delirium to deep coma. Patients with acutely altered mental status associated with encephalopathy have higher mortality rates $(49 \%)$ than patients with pre-existing mental status changes (41\%) or a normal mental status (26\%) [1] (Figures 1, 2, 3, 4, 5, 6, 7, 8 and 9).

\footnotetext{
* Correspondence: NingLinju@hotmail.com

${ }^{\dagger}$ Equal contributors

Department of General Surgery, Jinling Hospital, Medical School of Nanjing University, 305 East Zhongshan Road, Nanjing 210002, Jiangsu Province, China
}

Previous studies have established that inflammatory cytokine release and oxidative stress injury are major pathophysiological mechanisms of sepsis, resulting in injury to system tissues and organs [3,4]. Further studies have shown that the mechanisms underlying sepsis are related to cytokine generation and oxidative stress injury $[3,5]$. These effects can have several deleterious consequences, including nerve cell apoptosis and necrosis [6-8], neuronal bioenergetic failure and cerebral oxidative metabolism injury [9], axonal injury and brain tissue edema $[10,11]$, neurotransmitter transporter inhibition [12], and destruction of the blood-brain barrier [7]. A number of studies have confirmed that anti-inflammatory cytokines and reduction in oxidative stress have significant protective effects against brain injury [8,13-17]. Therefore, the inhibition of inflammation and oxidative stress can prevent brain tissue injury and ameliorate SAE.

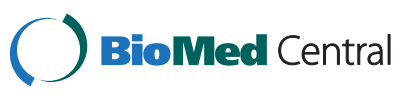




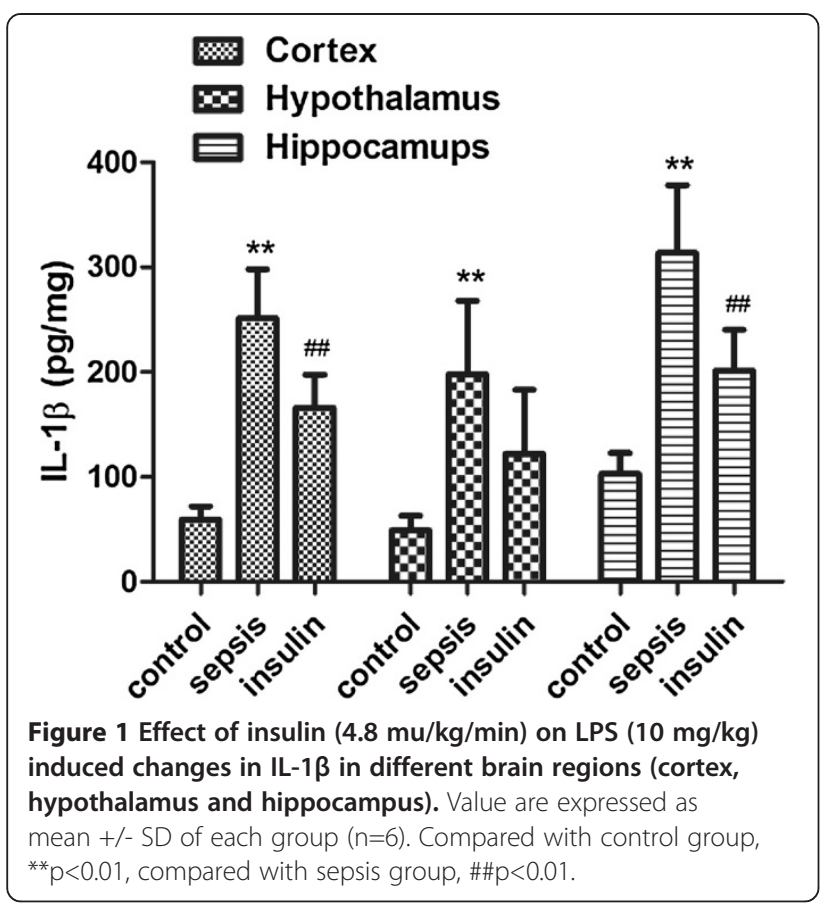

In recent years, controversies have arisen regarding insulin therapy in critically ill patients. In particular, the results of 2 milestone investigations conducted between 2001 and 2009 showed contradictory mortality benefits $[18,19]$. There are conflicting opinions on whether insulin therapy itself, in addition to the modification of glucose levels (regulated by insulin), is suitable for critical

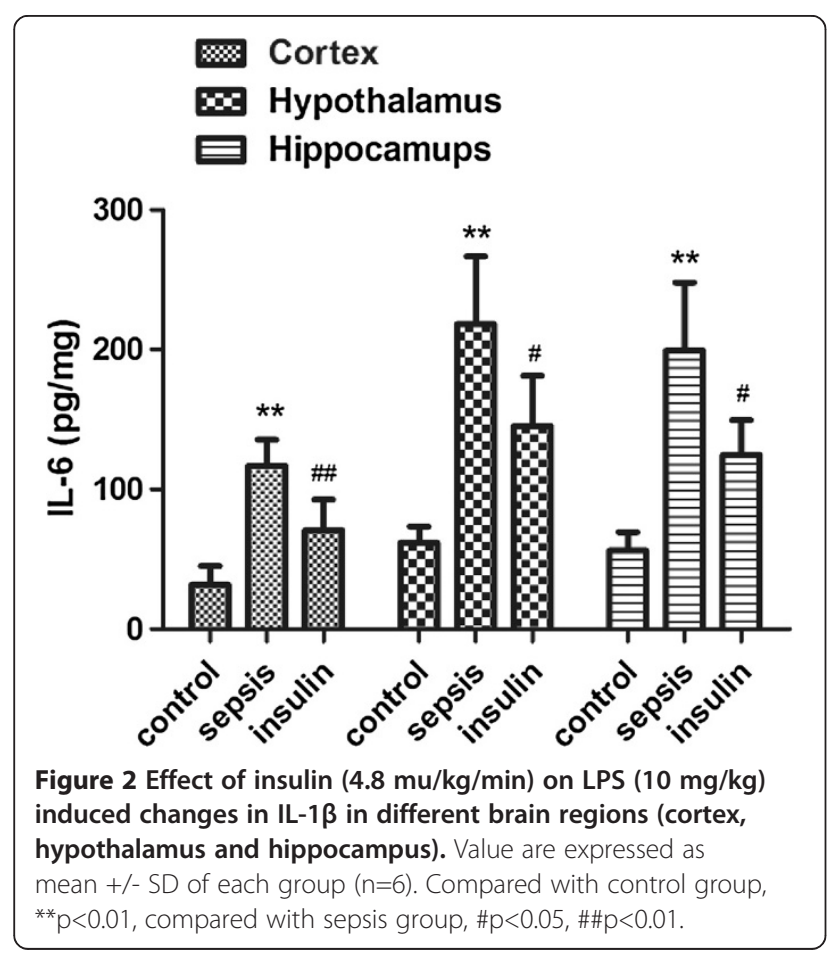

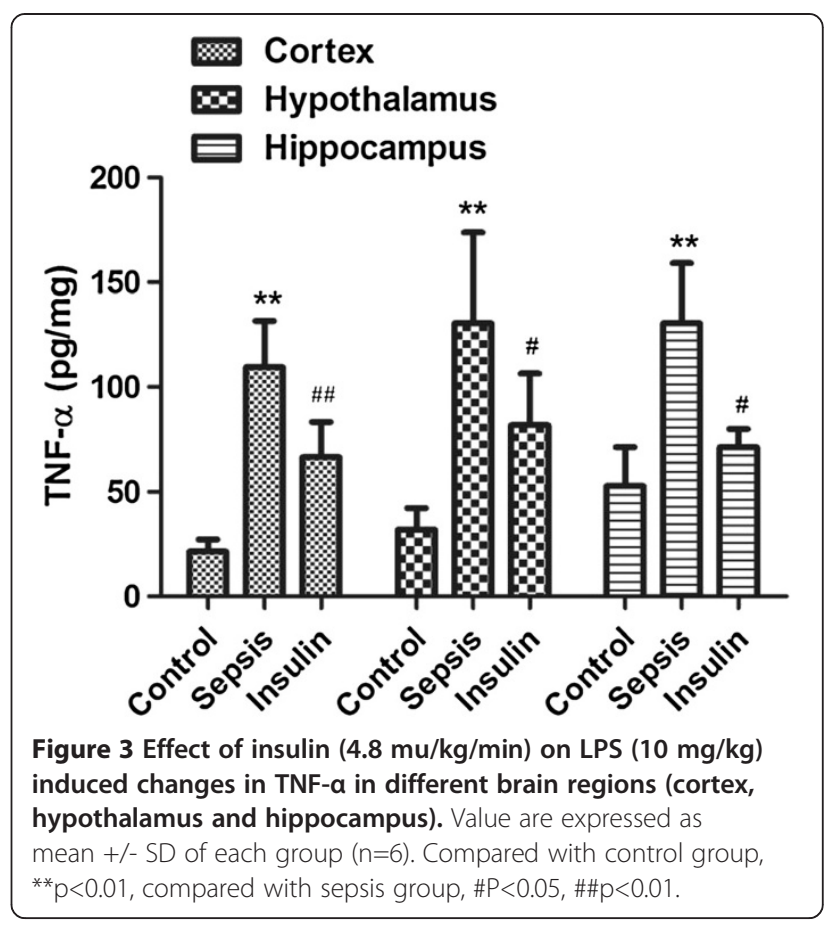

care patients. Insulin therapy provides better controllability and maneuverability in animal experiments and therefore has obvious benefits in animal models. In addition to the regulation of glucose levels, insulin therapy has important immunomodulatory effects in septic patients. Previous studies conducted by our group and others have demonstrated that insulin therapy can directly inhibit the

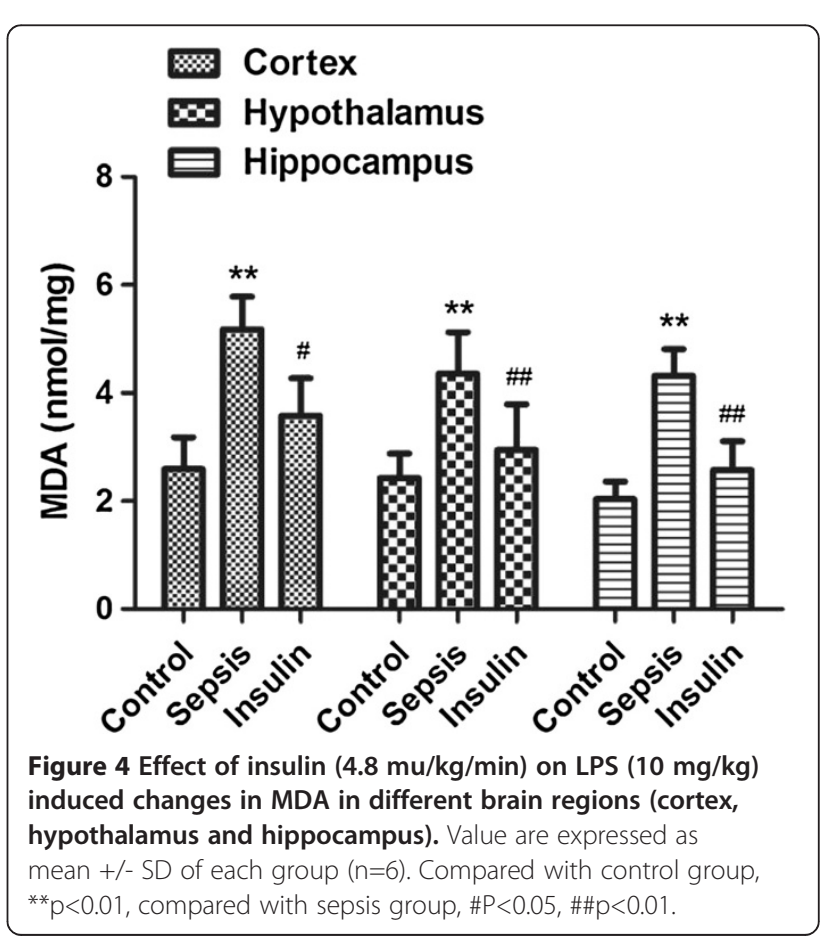




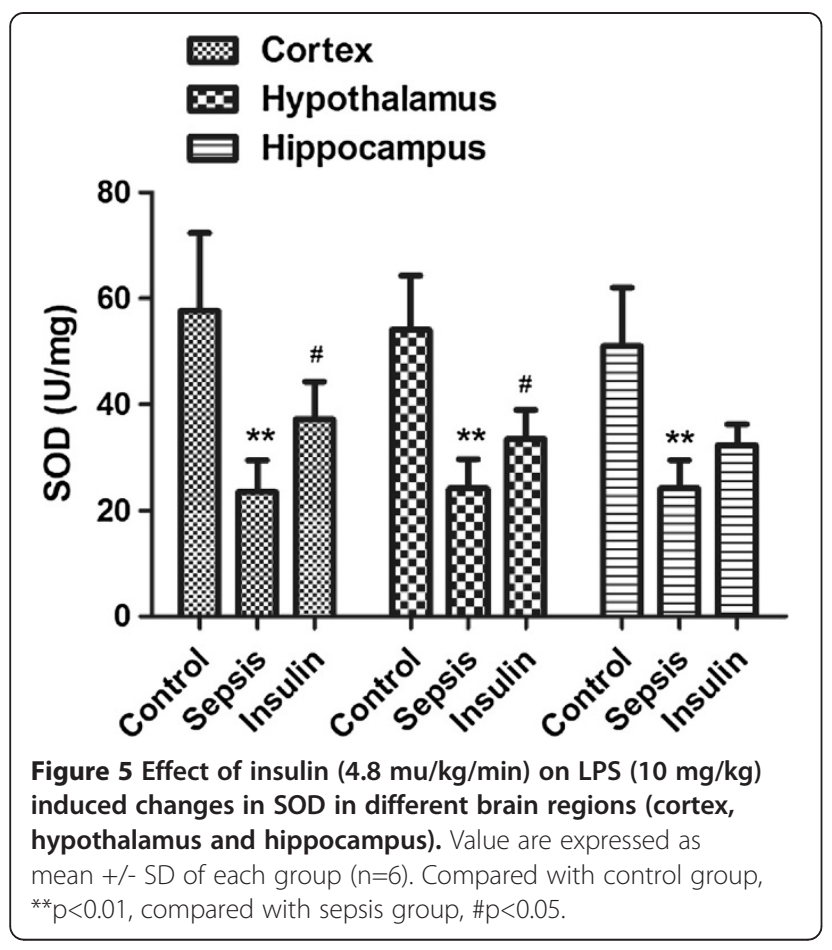

release of cytokines such as IL-1, IL-6, and TNF-a under septic conditions $[4,20]$. Furthermore, it can also inhibit the transcription factor NF- $\mathrm{KB}$ with subsequent downregulation of proinflammatory cytokines [21]. In addition, insulin can suppress oxidative stress by ameliorating

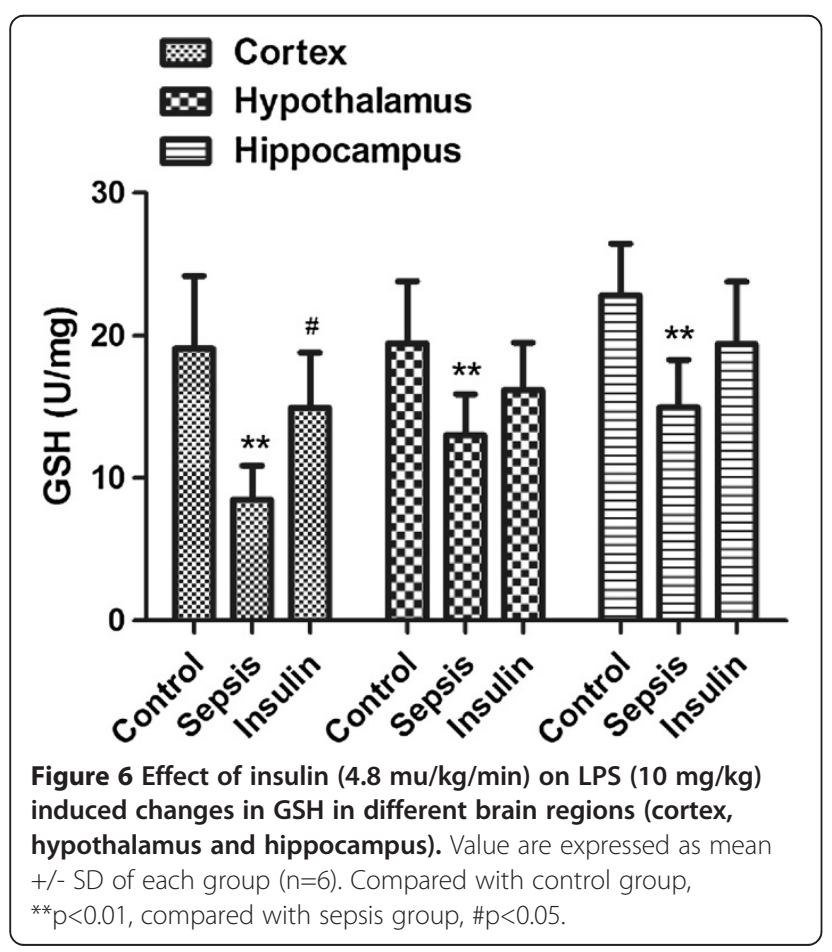

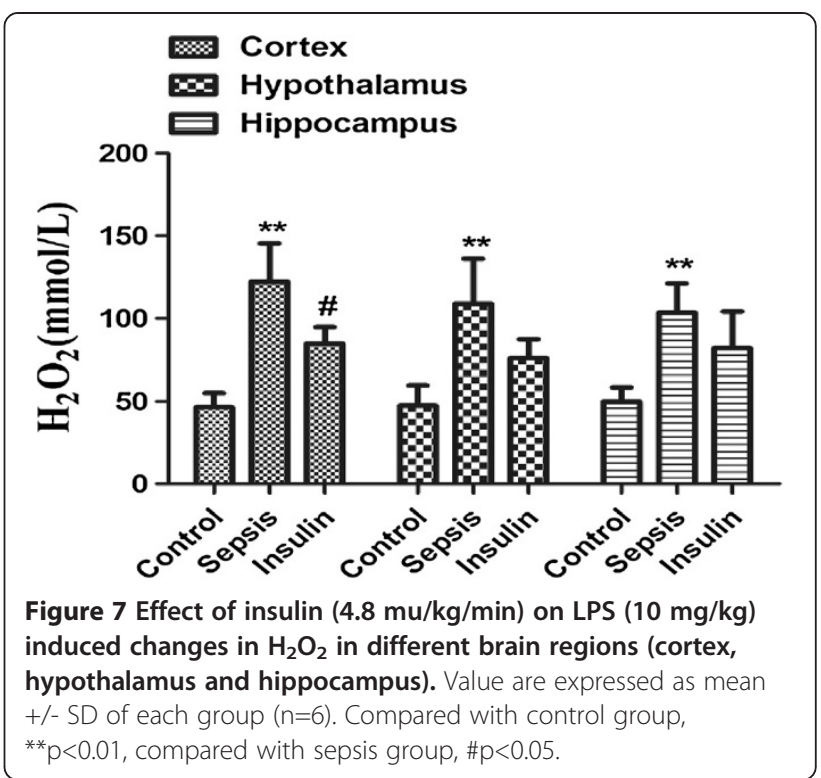

mitochondrial function or inhibiting the release of cytokines in septic patients and animals [21,22].

At present, studies of insulin therapy for critical care subjects focus on peripheral tissues, and very few studies assessing whether insulin can influence cerebral tissues of septic patients have been reported. Therefore, in this study, we aimed to explore whether insulin therapy can inhibit the production of cytokines (IL-1, IL-6, and TNF-a) and oxidative stress injury of the brain tissue in septic rats. Our findings may provide a theoretical basis for the clinical treatment of SAE.

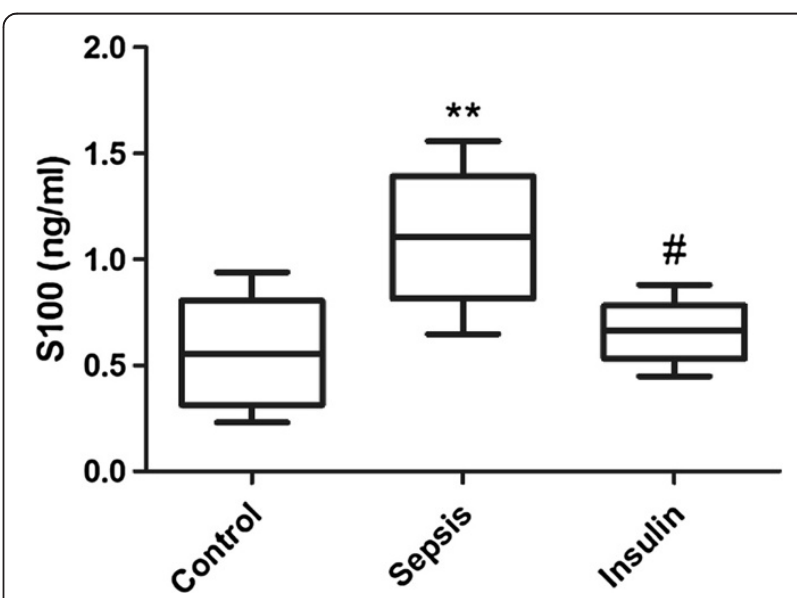

Figure 8 Effect of insulin $(4.8 \mathrm{mu} / \mathrm{kg} / \mathrm{min})$ on LPS $(10 \mathrm{mg} / \mathrm{kg})$ induced changes in $\mathbf{S 1 0 0}$ in serum. Value are expressed as mean $+/$ - SD of each group $(n=6)$. Compared with control group, ${ }^{* *} p<0.01$, compared with sepsis group, $\# p<0.05$. 


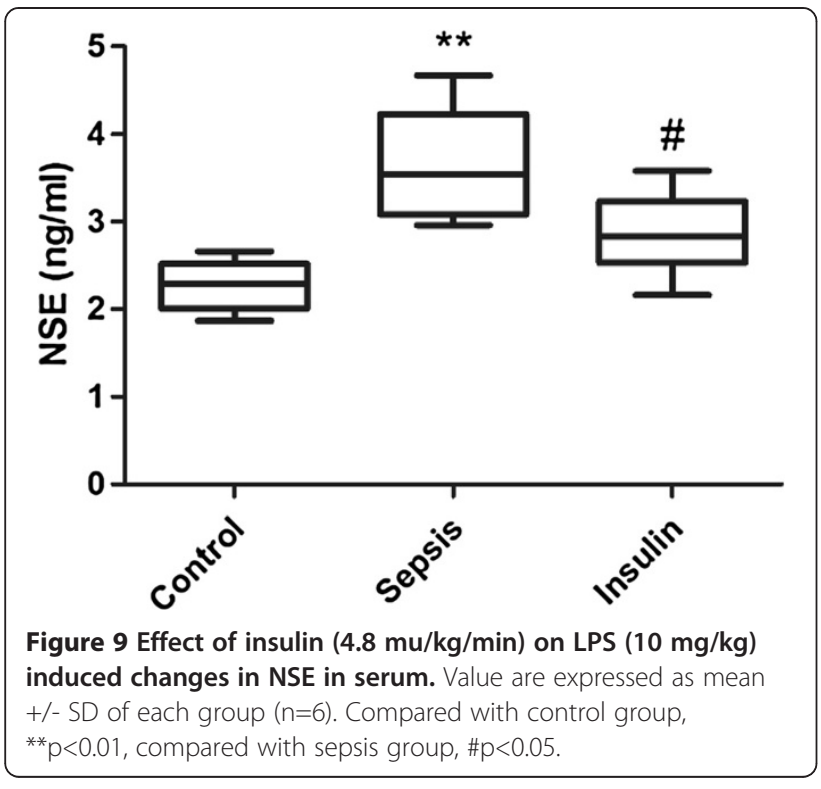

\section{Materials and methods \\ Animals}

In this study, we used 54 adult male Sprague-Dawley rats, weighing $280 \pm 20 \mathrm{~g}$, from the animal center of Jinling Hospital. The Institutional Animal Care Committee approved the study protocol. The Association accredits the animal care facility for Assessment and Accreditation of Laboratory Animal Care. Rats were housed in mesh cages in a $25^{\circ} \mathrm{C}$ room, illuminated in 12-h light: 12-h dark cycles. The animals were allowed to acclimatize to their environment for $7 \mathrm{~d}$ before the start of the study. They were provided with standard rodent chow and water ad libitum. The rats were fasted for $12 \mathrm{~h}$ immediately before the experiment.

\section{Animal preparation}

Rats were anesthetized intraperitoneally with phenobarbital sodium $(60 \mathrm{mg} / \mathrm{kg}$ ). Catheters (PE-50, PE-10; BectonDickinson, Sparks, MD) were implanted into the right femoral vein for the infusion of insulin and dextrose solutions via a micropump (provided by the Research Center for Analytical Instrument, Zhejiang University). The catheters were filled with saline containing heparin sodium. About $1 \mathrm{~mm}$ of the tail tip was cut for monitoring blood glucose levels. The scab of the incision was abscised with $75 \%$ alcohol every time. The area around the incision was gently squeezed and the first drop of blood was discarded; the next drop was used for monitoring using an Elite glucometer (Bayer, Elkhart, IN).

\section{Group distribution and insulin infusion strategy}

After the animals were prepared for the experiments, they were divided randomly into 3 groups as follows: control group $(n=12)$, LPS group $(n=12)$, and insulin treatment group $(\mathrm{n}=12)$. The sepsis model was mimicked by intraperitoneal injection of $10 \mathrm{mg} / \mathrm{kg}$ LPS (Escherichia coli serotype 055:B5; Sigma, St. Louis, MO). The rats in the insulin treatment group received a continuous infusion of insulin (Humulin R, Eli Lilly \& Co., Indianapolis, IN) at a constant rate of $4.8 \mathrm{mU} \cdot \mathrm{min}^{-1} \cdot \mathrm{kg}^{-1}$ for $6 \mathrm{~h}$ after LPS stimulation. Blood glucose was maintained at 140 $180 \mathrm{mg} / \mathrm{dL}$ by varying the infusion rate of a $50 \%$ dextrose solution. The LPS group was injected intraperitoneally with $10 \mathrm{mg} / \mathrm{kg}$ LPS only. The control group received an intraperitoneal injection of an equal volume of sterile saline only. The rats remained anesthetized for the duration of the experiment by the continuous infusion of phenobarbital sodium.

At the end of the infusion, the rats were killed with an overdose of phenobarbital sodium. The frontal cortex, hippocampus, and hypothalamus were dissected and stored at $-80^{\circ} \mathrm{C}$ until analysis.

\section{Determination of protein concentrations of inflammatory cytokines in cerebral tissues}

To determine the protein concentrations of TNF-a, IL-1 $\beta$, and IL- 6 in cerebral tissues (cortex, hypothalamus, and hippocampus), the tissues were diluted $(40 \% \mathrm{w} / \mathrm{v})$ with $0.01 \mathrm{~mol} / \mathrm{L}$ phosphate-buffered saline, $\mathrm{pH}$ 7.4, containing a protease inhibitor cocktail (Roche, Indianapolis, IN), and homogenized. The homogenates were then centrifuged at $7,500 \times g$ for $20 \mathrm{~min}$ at $4^{\circ} \mathrm{C}$. The levels of TNF-a, IL- $1 \beta$, and IL- 6 in the supernatant were determined by enzyme-linked immunosorbent assay performed using commercial kits (R\&D Systems, Minneapolis, MN) in accordance with the manufacturer's instructions. The results are expressed as $\mathrm{pg} / \mathrm{mg}$ of brain tissue.

\section{Measurements of antioxidants and oxidant indices in brain tissues}

The tissue homogenates were utilized for the determination of antioxidants (SOD and GSH) and oxidant indices (MDA) using commercial analysis kits (Nanjing Jiancheng Bioengineering Institute, China). SOD and GSH activities of the brain tissues (cortex, hypothalamus, and hippocampus; $n=6 /$ region/group) are expressed in terms of $\mathrm{U} / \mathrm{mg}$ protein, and MDA concentrations are expressed in $\mathrm{nmol} / \mathrm{mg}$ ( $\mathrm{n}=6$ /group).

\section{Measurements of $\mathrm{H}_{2} \mathrm{O}_{2}$ in brain tissues}

The tissue homogenates were utilized for the determination of $\mathrm{H}_{2} \mathrm{O}_{2}$ using commercial analysis kits (Nanjing Jiancheng Bioengineering Institute, China). The concertrations of $\mathrm{H}_{2} \mathrm{O}_{2}$ in brain tissue $(n=6 /$ regions/group) were expressed in terms of $\mathrm{mmol} / \mathrm{L}$. 


\section{Detection of serum S100 and neuron-specific enolase}

Blood samples were collected from the femoral vein at $6 \mathrm{~h}$ after insulin infusion for the measurement of S100 and neuron-specific enolase (NSE) levels. The blood was allowed to clot for 20-30 $\mathrm{min}$ at room temperature and then centrifuged and frozen at temperatures lower than $-70^{\circ} \mathrm{C}$. Serum S100 and NSE levels were quantified with an enzyme-linked immunosorbent assay (R\&D, USA) according to the manufacturer's instructions.

\section{Statistical analysis}

Data are expressed as mean \pm standard deviation (SD). Statistical analysis was performed using ANOVA. All data were analyzed using the SPSS software (Statistical Package for the Social Sciences, version 20.0, for Windows, SPSS, Chicago, IL). A p value $<0.05$ was considered significant.

\section{Results}

Variation in the protein concentrations of the cytokines IL-1 $\beta$, IL-6, and TNF-a in cerebral tissues

The protein concentrations of the cytokines IL-1 $\beta$, IL-6, and TNF-a in the cortex, hypothalamus, and hippocampus significantly increased after intraperitoneal injection of $10 \mathrm{mg} / \mathrm{kg}$ LPS (vs. control group, $\mathrm{p}<0.01$ ). When insulin was injected at $4.8 \mathrm{mU} \cdot \mathrm{kg}^{-1} \cdot \mathrm{min}^{-1}$ for $6 \mathrm{~h}$, the IL- 6 and TNF-a levels decreased significantly in the cortex, hypothalamus, and hippocampus (vs. sepsis group, $\mathrm{p}<0.05)$. Although the IL-1 level decreased only mildly in the hypothalamus $(122.11 \pm 61.03$ vs. $198 \pm 70.49$ in the sepsis group, $\mathrm{p}=0.21$ ), it significantly decreased in the cortex and hippocampus (vs. sepsis group, $\mathrm{p}<0.05$ ).

\section{Variation in antioxidant and oxidant indices in cerebral tissues}

After injection of $10 \mathrm{mg} / \mathrm{kg}$ LPS, the MDA concentrations in all brain regions (cortex, hypothalamus, and hippocampus) notably increased (vs. control group, $\mathrm{p}<0.01$ ), but the GSH and SOD activities in all brain regions significantly decreased (vs. control group, $\mathrm{p}<0.01$ ). When insulin was injected at $4.8 \mathrm{mU} \cdot \mathrm{kg}^{-1} \cdot \mathrm{min}^{-1}$ for $6 \mathrm{~h}$, IL- 6 and MDA levels decreased significantly in all brain regions (vs. sepsis group, $\mathrm{p}<0.05$ ). SOD and GSH activities were upregulated to different degrees in all brain regions; SOD upregulation was most obvious in the cortex and hypothalamus (vs. sepsis group, $\mathrm{p}<0.05$ ), whereas GSH upregulation was most significant in the cerebral cortex (vs. sepsis group, $\mathrm{p}<0.05$ ).

\section{Variation in ROS system indices $\mathrm{H}_{2} \mathrm{O}_{2}$ in cerebral tissues}

The $\mathrm{H}_{2} \mathrm{O}_{2}$ concentrations in all brain regions were notably increased (vs. control group, $\mathrm{p}<0.01$ ), after injection of $10 \mathrm{mg} / \mathrm{kg}$ LPS. When insulin was injected by $4.8 \mathrm{mU} /(\mathrm{kg} \cdot \mathrm{min})$ for 6 hours, we found that $\mathrm{H}_{2} \mathrm{O}_{2}$ were decreased sigificantly in cortex (vs. sepsis group, $\mathrm{p}<0.05$ ). and the $\mathrm{H}_{2} \mathrm{O}_{2}$ were also decreased moderatly in hypothalamus and hippocampu, although both no significant difference (vs. sepsis group, $\mathrm{p}>0.05$ ).

\section{Variation in the serum protein levels of S100B and NSE}

The concentrations of S100 and NSE in the serum notably increased (vs. control group, $\mathrm{p}<0.01$ ) after injection of $10 \mathrm{mg} / \mathrm{kg}$ LPS. However, when insulin was injected at $4.8 \mathrm{mU} \cdot \mathrm{kg}^{-1} \cdot \mathrm{min}^{-1}$ for $6 \mathrm{~h}$, the serum S100 and NSE levels significantly decreased (vs. sepsis group, $\mathrm{p}<0.05$ ).

\section{Discussion}

During sepsis, the brain may be one of the first organs affected [23,24]. SAE, a diffuse brain dysfunction, can be detected in up to $50-70 \%$ of septic patients, and patients with acute SAE have a high mortality rate $(49 \%)[1,2]$. Several lines of evidence indicate that an inflammatory cascade and oxidative stress injury are the main mechanisms of SAE. However, at present, the establishment of therapeutic strategies for the treatment of SAE in clinical practice is problematic.

Under septic conditions, the expression of cytokines (e.g., IL-1, IL-6, TNF-a, and IL-10) is significantly upregulated in cerebral tissues. In agreement with this, our results show that the protein concentrations of the cytokines IL-1, IL-6, and TNF-a notably increased in the cortex, hippocampus, and hypothalamus of septic rats. Numerous studies suggest that cytokines cause brain toxicity. The reported injurious effects of cytokines include nerve cell apoptosis and necrosis [6-8], neuronal bioenergetic failure and cerebral oxidative metabolism injury [9], axonal injury and brain tissue edema [10,11], neurotransmitter transporter inhibition [12], and destruction of the blood-brain barrier [7].

An imbalance between oxidants and antioxidants in favor of the oxidants, potentially leading to damage, is termed "oxidative stress". Oxidants are formed as a normal product of aerobic metabolism, but they can also be produced at elevated rates under pathophysiological conditions [25]. The antioxidant systems in the body include SOD, glutathione peroxidase (GSH-Px), catalase, and GSH $[26,27]$. MDA is the main oxidation product of peroxidized polyunsaturated fatty acids, and an increased MDA level is an important indication of lipid peroxidation [26,27]. The brain is particularly susceptible to oxidative stress because of its high metabolic rate, relatively low capacity for cellular regeneration [28], and low antioxidant capacity due to a lack of reduced GSH [29-31]. During sepsis, oxidative stress injury is the main pathophysiological mechanism of SAE. Our experimental results showed that the levels of the antioxidants SOD and GHS notably decreased in septic rats in every region of the brain (hippocampus, hypothalamus, and cortex), whereas the 
MDA levels notably increased. These results are similar to previous observations that an imbalance exists between oxidants and antioxidants during sepsis.

Reactive oxygen species (ROS) including superoxide $\mathrm{O}_{2}^{-}$, hydrogen peroxide $\left(\mathrm{H}_{2} \mathrm{O}_{2}\right)$, and hydroxyl radicals are generated in both normal and pathological, biological processes. ROS system can significantly were activated and participated in the pathophysiology process of sepsis [32]. The study found similar, in sepsis, $\mathrm{H}_{2} \mathrm{O}_{2}$ was increased significantly. The present study found that $\mathrm{H}_{2} \mathrm{O}_{2}$ significantly reduced the GPx, SOD, and CAT activities, while MDA level exposed to $\mathrm{H}_{2} \mathrm{O}_{2}$ was elevated,indicating disruptions of the endogenous antioxidant enzymes [33]. Agents that inhibit the production of reactive oxygen species or increase the antioxidant defense may prevent apoptosis and protect cells from oxygen radicals damage [33]. Insulin can prevent mitochondrial generation of $\mathrm{H}_{2} \mathrm{O}_{2}$ in normal rat neuronal cultures [34]. In our results showed $\mathrm{H}_{2} \mathrm{O}_{2}$ were decreased in cortex, hypothalamus and hippocampus in different degree when insulin was injected by $4.8 \mathrm{mU} \cdot \mathrm{kg}^{-1} \cdot \mathrm{min}^{-1}$ for 6 hours.

Above-mentioned results show that insulin can inhibit inflammatory cytokines and the oxidative stress response. The interaction between cytokines and oxidative stress has also been recently investigated. Cytokines have been reported to increase the neutrophil oxidative respiratory burst [35]; however, oxidative stress can be an initiator of cytokine release and cell damage [36]. Therefore, with respect to SAE, it might be useful to inhibit the inflammatory response and correct the imbalance between oxidants and antioxidants in brain tissues. In addition to the regulation of blood glucose levels, insulin plays important roles in immune regulation and the inhibition of oxidative stress injury. Our previous studies and a number of other reports have demonstrated that insulin can significantly reduce the release of inflammatory cytokines and improve the prognosis of critically ill patients [20]. To date, studies of insulin therapy for critical care subjects have focused on peripheral tissues, and the effects of insulin in the cerebral tissues of septic patients have not been thoroughly investigated. Therefore, in our experiment, we infused insulin intravenously at $4.8 \mathrm{mU} \cdot \mathrm{kg}^{-1} \cdot \mathrm{min}^{-1}$ and maintained the blood glucose level at $140-180 \mathrm{mmol} / \mathrm{dL}$ by intravenous infusion of a $50 \%$ dextrose solution. After $6 \mathrm{~h}$ of insulin therapy, we found that cytokine concentrations notably decreased and oxidative stress injury in the cortex, hypothalamus, and hippocampus was alleviated in septic rats.

Serum S100B and NSE are specific biomarkers of cerebral injury [37,38]. S100B is most abundant in glial cells of the CNS, mainly in astrocytes, while NSE is present almost exclusively in the cytoplasm of neurons $(\gamma-\gamma$ isoenzyme) and neuroendocrine cells ( $\alpha-\gamma$ isoenzyme). Therefore, in our next study, we will further examine the serum content of S100 and NSE. In the present study, we found that the serum levels of S100 and NSE were notably increased after injection of $10 \mathrm{mg} / \mathrm{kg}$ LPS. However, when insulin was injected at $4.8 \mathrm{mU} \cdot \mathrm{kg}^{-1} \cdot \mathrm{min}^{-1}$ for $6 \mathrm{~h}$, we found that the serum levels of S100 and NSE significantly decreased. Therefore, the results of this study indicate that insulin can inhibit cerebral injury.

In conclusion, our results show that insulin can inhibit inflammatory cytokines and the oxidative stress response and consequently improve brain tissue damage. The findings of this study may provide a basis for the development of treatment strategies for SAE in clinical practice.

\section{Abbreviations}

SAE: Sepsis-associated encephalopathy; CNS: Central nervous system; NSE: Neuron-specific enolase.

\section{Competing interests}

The authors declare that they have no competing interests.

\section{Authors' contributions}

QC, JShi and JShen participated in the collection of data. NL and WY conceived and designed this study. TG, JZ and FX performed the statistical analysis. QC, JShi and JShen wrote the first draft of the paper and $J$ commented on the draft. All the other authors provided comments and approved the final manuscript. All authors read and approved the final manuscript.

\section{Acknowledgements}

This research was supported by the National Natural Science Foundation (81270884), Jiangsu Province Special Program of Medical Science (BL2012006), Grant for 12th five-year plan major project (AWS11J03), Grant for 12th five-year plan major project (WS12J001), and Jiangsu Province's Key Medical Talent Program (RC2011128).

Received: 6 July 2013 Accepted: 8 May 2014

Published: 20 June 2014

\section{References}

1. Gofton TE, Young GB: Sepsis-associated encephalopathy. Nat Rev Neurol 2012, 8(10):557-566.

2. Maramattom BV: Sepsis associated encephalopathy. Neurol Res 2007, 29(7):643-646.

3. Zhou J, Chen Y, Huang GQ, Li J, Wu GM, Liu L, Bai YP, Wang J: Hydrogenrich saline reverses oxidative stress, cognitive impairment, and mortality in rats submitted to sepsis by cecal ligation and puncture. J Surg Res 2012, 178(1):390-400.

4. Jeschke $M G$, Klein D, Bolder U, Einspanier R: Insulin attenuates the systemic inflammatory response in endotoxemic rats. Endocrinology 2004, 145(9):4084-4093.

5. Salvemini D, Cuzzocrea S: Oxidative stress in septic shock and disseminated intravascular coagulation. Free Radic Biol Med 2002, 33(9):1173-1185.

6. Stolp HB, Dziegielewska KM: Review: Role of developmental inflammation and blood-brain barrier dysfunction in neurodevelopmental and neurodegenerative diseases. Neuropathol Appl Neurobiol 2009, 35(2):132-146.

7. Aktas O, Ullrich O, Infante-Duarte C, Nitsch R, Zipp F: Neuronal damage in brain inflammation. Arch Neurol 2007, 64(2):185-189.

8. Consales G, De Gaudio AR: Sepsis associated encephalopathy. Minerva Anestesiol 2005, 71(1-2):39-52.

9. Berg RM, Moller K, Bailey DM: Neuro-oxidative-nitrosative stress in sepsis. J Cereb Blood Flow Metab 2011, 31(7):1532-1544.

10. Jiang W, Desjardins P, Butterworth RF: Cerebral inflammation contributes to encephalopathy and brain edema in acute liver failure: protective effect of minocycline. J Neurochem 2009, 109(2):485-493.

11. Nimmo AJ, Cernak I, Heath DL, Hu X, Bennett CJ, Vink R: Neurogenic inflammation is associated with development of edema and functional 
deficits following traumatic brain injury in rats. Neuropeptides 2004, 38(1):40-47.

12. Denes A, Thornton P, Rothwell NJ, Allan SM: Inflammation and brain injury: acute cerebral ischaemia, peripheral and central inflammation. Brain Behav Immun 2010, 24(5):708-723.

13. Meyer U, Murray PJ, Urwyler A, Yee BK, Schedlowski M, Feldon J: Adult behavioral and pharmacological dysfunctions following disruption of the fetal brain balance between pro-inflammatory and IL-10-mediated anti-inflammatory signaling. Mol Psychiatry 2008, 13(2):208-221.

14. Londono D, Carvajal J, Strle K, Kim KS, Cadavid D: IL-10 Prevents apoptosis of brain endothelium during bacteremia. J Immunol 2011, 186(12):7176-7186.

15. Wang ZJ, Liang CL, Li GM, Yu CY, Yin M: Neuroprotective effects of arachidonic acid against oxidative stress on rat hippocampal slices. Chem Biol Interact 2006, 163(3):207-217.

16. Vajragupta O, Boonyarat C, Murakami Y, Tohda M, Musatmoto K, Olson AJ, Watanabe $\mathrm{H}$ : A novel neuroprotective agent with antioxidant and nitric oxide synthase inhibitory action. Free Radic Res 2006, 40(7):685-695.

17. Licinio J, Mastronardi C, Wong ML: Pharmacogenomics of neuroimmune interactions in human psychiatric disorders. Exp Physiol 2007, 92(5):807-811.

18. van den Berghe G, Wouters $P$, Weekers F, Verwaest C, Bruyninckx F, Schetz M, Vlasselaers D, Ferdinande P, Lauwers P, Bouillon R: Intensive insulin therapy in critically ill patients. N Eng/ J Med 2001, 345(19):1359-1367.

19. Finfer S, Chittock DR, Su SY, Blair D, Foster D, Dhingra V, Bellomo R, Cook D, Dodek P, Henderson WR, Hebert PC, Heritier S, Heyland DK, McArthur C, McDonald E, Mitchell I, Myburgh JA, Norton R, Potter J, Robinson BG, Ronco $\mathrm{JJ}$ : Intensive versus conventional glucose control in critically ill patients. N Engl J Med 2009, 360(13):1283-1297.

20. Zou B, Chen Q, Tang S, Gao T, Zhang J, Xi F, Yu W: Timing of insulin therapy affects the inflammatory response in endotoxemic rats. Inflammation 2012, 35(2):723-729.

21. Viardot A, Grey ST, Mackay F, Chisholm D: Potential antiinflammatory role of insulin via the preferential polarization of effector T cells toward a $T$ helper 2 phenotype. Endocrinology 2007, 148(1):346-353.

22. Vanhorebeek I, De Vos R, Mesotten D, Wouters PJ, De Wolf-Peeters C, Van den Berghe G: Protection of hepatocyte mitochondrial ultrastructure and function by strict blood glucose control with insulin in critically ill patients. Lancet 2005, 365(9453):53-59.

23. Milbrandt EB, Angus DC: Bench-to-bedside review: critical illnessassociated cognitive dysfunction-mechanisms, markers, and emerging therapeutics. Crit Care 2006, 10(6):238.

24. Ebersoldt M, Sharshar T, Annane D: Sepsis-associated delirium. Intensive Care Med 2007, 33(6):941-950.

25. Sies H: Oxidative stress: oxidants and antioxidants. Exp Physiol 1997, 82(2):291-295

26. Zhan XA, Wang $M, X u Z R$, Li WF, Li JX: Effects of fluoride on hepatic antioxidant system and transcription of Cu/Zn SOD gene in young pigs. J Trace Elem Med Biol 2006, 20(2):83-87.

27. Mruk DD, Silvestrini B, Mo MY, Cheng CY: Antioxidant superoxide dismutase - a review: its function, regulation in the testis, and role in male fertility. Contraception 2002, 65(4):305-311.

28. Andersen JK: Oxidative stress in neurodegeneration: cause or consequence. Nat Med 2004, 10(Suppl):S18-S25.

29. Elmarakby AA, Sullivan JC: Relationship between oxidative stress and inflammatory cytokines in diabetic nephropathy. Cardiovasc Ther 2012, 30(1):49-59.

30. Chong ZZ, Li F, Maiese K: Oxidative stress in the brain: novel cellular targets that govern survival during neurodegenerative disease. Prog Neurobiol 2005, 75(3):207-246.

31. Curtin JF, Donovan M, Cotter TG: Regulation and measurement of oxidative stress in apoptosis. J Immunol Methods 2002, 265(1-2):49-72.

32. Trentadue R, Fiore F, Massaro F, Papa F, luso A, Scacco S, Santacroce L, Brienza N: Induction of mitochondrial dysfunction and oxidative stress in human fibroblast cultures exposed to serum from septic patients. Life Sci 2012, 91(7-8):237-243.

33. Abd MN, Mohamed N, Shuid AN: Effects of Low-Dose versus High-Dose gamma-Tocotrienol on the Bone Cells Exposed to the Hydrogen Peroxide-Induced Oxidative Stress and Apoptosis. Evid Based Complement Alternat Med 2012, 2012:680834.

34. Muller AP, Haas CB, Camacho-Pereira J, Brochier AW, Gnoatto J, Zimmer ER, de Souza DO, Galina A, Portela LV: Insulin prevents mitochondrial generation of $\mathrm{H}(2) \mathrm{O}(2)$ in rat brain. Exp Neurol 2013, 247:66-72.
35. Wittmann S, Rothe G, Schmitz G, Frohlich D: Cytokine upregulation of surface antigens correlates to the priming of the neutrophil oxidative burst response. Cytometry A 2004, 57(1):53-62.

36. Crapo JD: Oxidative stress as an initiator of cytokine release and cell damage. Eur Respir J 2003, 44(Suppl):4s-6s.

37. Jeter CB, Hergenroeder GW, Hylin MJ, Redell JB, Moore AN, Dash PK: Biomarkers for the diagnosis and prognosis of mild traumatic brain injury/concussion. J Neurotrauma 2013, 30(8):657-670.

38. Papa L, Ramia MM, Kelly JM, Burks SS, Pawlowicz A, Berger RP: Systematic Review of Clinical Research on Biomarkers for Pediatric Traumatic Brain Injury. J Neurotrauma 2013, 30(5):324-338.

doi:10.1186/1476-9255-11-18

Cite this article as: Chen et al: Insulin alleviates the inflammatory response and oxidative stress injury in cerebral tissues in septic rats. Journal of Inflammation 2014 11:18.

\section{Submit your next manuscript to BioMed Central and take full advantage of:}

- Convenient online submission

- Thorough peer review

- No space constraints or color figure charges

- Immediate publication on acceptance

- Inclusion in PubMed, CAS, Scopus and Google Scholar

- Research which is freely available for redistribution

Submit your manuscript at www.biomedcentral.com/submit
C Biomed Central 